\title{
Design and analysis of distributed photo-voltaic power station
}

\author{
Feng Peilei ${ }^{1}$, Wu Hesong*2, Zhang Mingsheng ${ }^{3}$, Wan Wenkui ${ }^{3}$ \\ ${ }^{1}$ School of Electrical and Information TechnologyYunnan Minzu University Kunming, China \\ ${ }^{2}$ Diqing Grid Bureau, Yunnan Grid Corporation Limited, Diqing StateDiqing, China \\ ${ }^{3}$ Kunming University of Science and Technology Oxbridge College Kunming, China
}

\begin{abstract}
After the location of the power station is determined, the construction scale of the solar grid connected photo-voltaic power station is mainly with the terrain conditions and the conditions of land use.The selection of solar cell components and installation methods, access to the power grid and other factors are related.In this paper, according to the existing construction conditions in the sewage plant, the area suitable for the layout of the solar cell array is selected.According to the structural characteristics of existing structures and the prediction of the power load in the sewage plant, the installed capacity of the plan is $4.9218 \mathrm{MWp}$. A $10 \mathrm{kV}$ installed switch-gear station is built, and the $110 \mathrm{kV}$ outlet is connected to the total distribution room power station. The project is completed at once.Solar energy is converted to DC power through photo-voltaic array composed of PV modules. After three phase inverter (DC-AC) is converted to three-phase alternating current, it is converted to AC power that meets the requirements of public power grid and directly connected to the public power grid through the step-up transformer.The construction and operation of photo-voltaic power stations will not cause pollution to the environment, and can also provide some clean energy, which can reduce the use of fossil fuels such as coal.
\end{abstract}

\section{Introduction}

The distribution of solar energy on the earth is related to latitude, altitude, geographical conditions and climate conditions ${ }^{[1]}$. The richness of the resource is generally expressed as the total annual total radiation and the total sunshine duration of the year.China is one of the countries with abundant solar energy resources, and the annual sunshine time of the total area above $2 / 3$ is more than 2000 hours.It includes the west of Tibet, the south of Xinjiang, Gansu and Inner Mongolia ${ }^{[2]}$.The daily sunshine hours in these areas are close to or more than $3000 \mathrm{~h}$, and the annual solar radiation exceeds $1750 \mathrm{~kW}$ $\mathrm{h} / \mathrm{m} 2$. The ratio of the monthly maximum and the minimum available day number is smaller and the annual change is more stable, which is the best area for the utilization of solar energy resources ${ }^{[3]}$.

\section{Data Analysis Of Solar Energy Resources}

The spatial distribution of solar energy resources in a certain area is detailed in the following figure 1.The annual average annual total radiation of the level of the area is about $4400 \sim 4600 \mathrm{MJ} / \mathrm{m}^{2}$. The conversion is 1222.2 1277.8kWh/m².

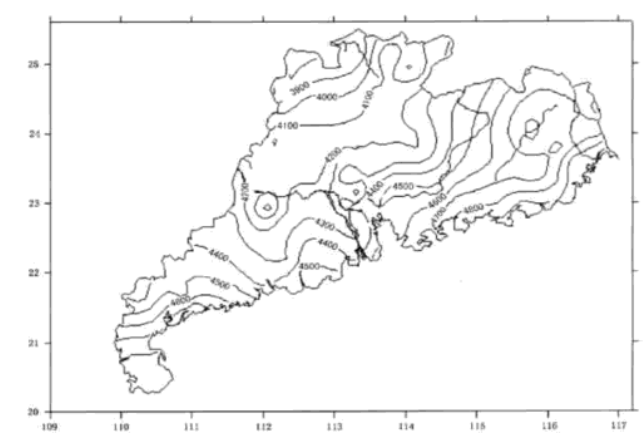

Figure 1.Distribution of solar energy resources in a certain area.

The solar radiation data in the NASA database and the Metonorm software are used to analyze the solar radiation data on the site.

Changes in total annual total radiation in 1984 2005, as shown in the following table1 (NASA)

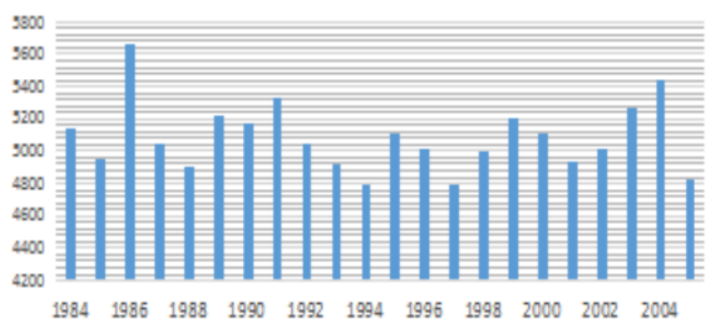

Figure 2. Total annual radiation levels of the site level of the site from 1984 to 2005 . 


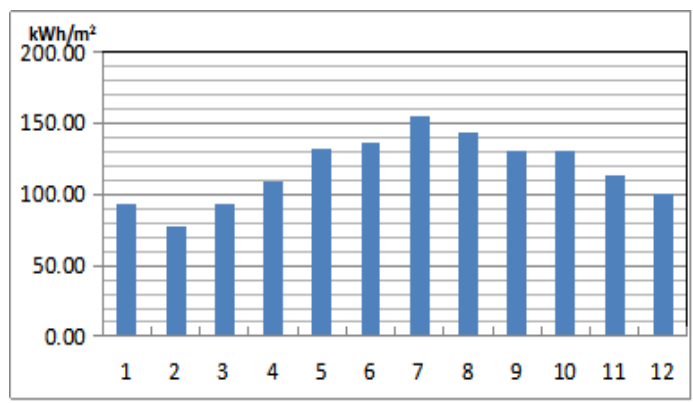

Figure 3. Average solar total radiation change histogram from 1984 to 2005

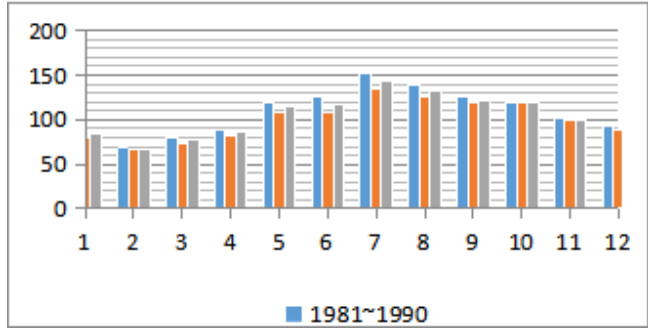

Figure 4. Meteonorm data histogram of total solar radiation from 1981 to 2010

Comparing the NASA database and the Meteonorm data, it is found that the monthly average radiation changes of the two databases are basically the same.The average annual representative value of each month in the project area is a single peak. In July August, is the largest and the second month, February is the minimum.From May to November, the amount of radiation was large, and the radiation from December to April was the smallest.The maximum and the minimum of the solar radiation difference is $67 \sim 84 \mathrm{kWh} / \mathrm{m}^{2}$, great changes during the year.According to historical experience, the amount of radiation provided by the NASA database is generally high. The solar radiation data of the Meteonorm database is close to the measured value.In this stage, the annual total solar radiation on the level of the site is $1205 \mathrm{~kW} \cdot \mathrm{h} / \mathrm{m}^{2}$.

\section{Application And Analysis Of Photo-Voltaic Cells}

The most important of the photo-voltaic power generation system is the photo-voltaic cell, which is the basic unit of collecting the sunlight to produce the electric energy.A number of photo-voltaic cells are synthesized together to form a photo-voltaic module.The main types of photo-voltaic cells are: crystal silicon photo-voltaic cells, amorphous silicon photo-voltaic cells [4].

At present, the market production and use of photo-voltaic cells are mostly made of crystalline silicon materials, which account for about 99.9\% in 2016. Amorphous silicon thin film batteries occupy most of the market of amorphous silicon batteries, [5]. It is also the most efficient in the large-scale production of silicon based photo-voltaic cells.Compared with monocrystalline silicon battery, polycrystalline silicon battery efficiency is reduced, but energy saving, silicon material saving, process cost and efficiency are relatively balanced.The market share of amorphous silicon thin film battery is gradually replaced by crystal silicon battery. In 2016, the output of amorphous silicon components accounted for about $0.1 \%$ of the total output of photo-voltaic components.
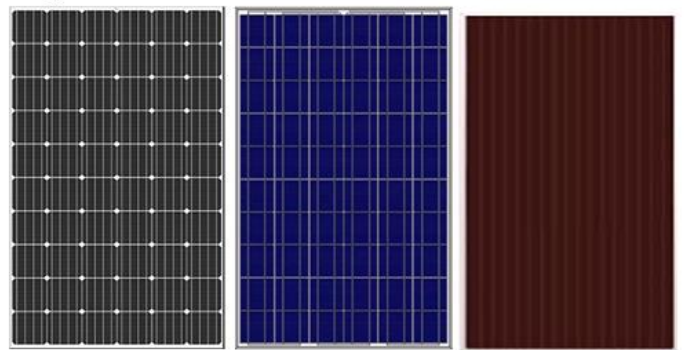

Figure 5. Monocrystalline, polysilicon and amorphous silicon thin film components

The large photo-voltaic grid connected power station should be selected with mature technology and high conversion efficiency.At present, it has already been produced in scale, and has become a widely used type of photo-voltaic components.It is mainly the monocrystalline silicon photo-voltaic module and the polysilicon photo-voltaic module.The main difference between the two components in the engineering application is that the photoelectric conversion efficiency of the monocrystalline silicon cell is slightly higher, and the layout aspect is slightly more economical.In the design of photo-voltaic power generation system, the installation form of PV module has great influence on the total solar radiation received by the system, thus affecting the power generation capability of PV power supply system. The operating mode of PV array has three types: fixed, adjustable and automatic tracking system. When selecting the operation mode of PV array, we should consider the comprehensive factors such as operation reliability, equipment price, maintenance cost after completion, failure rate and power generation efficiency.

\section{Design And Analysis Of Distributed Photovoltaic Power Station}

As a high energy consuming enterprise, the energy consumption of urban sewage plant mainly includes the following aspects:

1) the operation of the pump used to improve the sludge and sewage;2) energy for the supply of biological treatment;3) the operation of special machinery used for drainage;4) used in sludge treatment;5) testing, office and living facilities energy consumption.

The electric load used by the owner from December 2015 to November 2016 is as follows: 


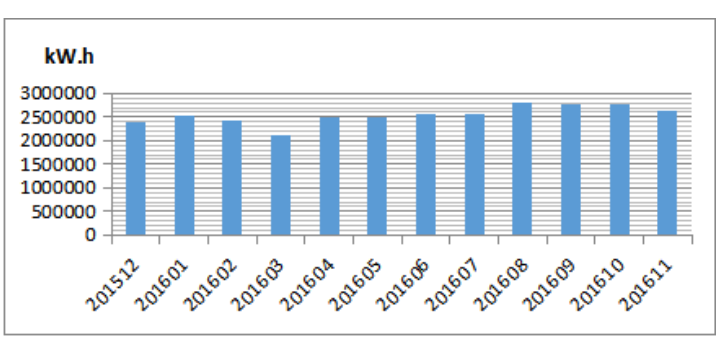

Figure 6. Electric load histogram

From the above chart, it can be seen that the power load of the sewage plant is more stable.The minimum value is $2103120 \mathrm{~kW} . \mathrm{h}$, the maximum value is $2799240 \mathrm{~kW} . \mathrm{h}$, and the average value is $2542790 \mathrm{~kW}$.h.According to the current situation of the basic load running in the field, the electric load in the waste water plant will float up and down in the future $2542790 \mathrm{~kW}$.h.The construction scale of solar grid connected photo-voltaic power station is mainly related to the terrain conditions, land use conditions, the selection of solar cell modules and their installation methods, and the ability of access to the power grid after the establishment of the power grid's location[6].We should speed up the development of other renewable energy sources such as wind energy and speed up the diversified utilization of solar energy.To promote the merger and reorganization of the photo-voltaic industry and the optimization and upgrading, vigorously promote the integration of photo-voltaic power generation with the building, and improve the scale of distributed utilization.Based on the local consumption of construction of large-scale photo-voltaic power plants, and actively carry out the solar thermal power generation demonstration.We will accelerate the development of integrated solar energy applications, and encourage the application of solar energy, heating and refrigeration, and the high temperature industry in solar energy ${ }^{[7]}$.

\section{Calculation of optimum angle of PV array}

The amount of solar radiation received on the inclined surface increases first and then decreases with the increase of the angle of the inclined plane. The change law of the symmetry of the angle of the oblique plane corresponding to the maximum value of the solar radiation.In the northern regions and plateau areas where the direct radiation components of the sun are relatively large, the amount of solar radiation received on the tilting fixed lower slope is obviously improved.In the areas where the solar scattering components are large in the South and in the cities with larger fog and haze, the role of the adjustable angle is lower.The tilt angle of the photo-voltaic array has a great influence on the efficiency of the photo-voltaic power generation system.For the fixed grid connected photo-voltaic power generation system, the dip angle is suitable for the maximum amount of radiation on the PV square tilting surface all the year.The total amount of radiation on the tilting surface of the PV module is the sum of the direct radiation, the amount of scattered radiation and the amount of ground reflection on the inclined plane.In engineering, the following formulas are used to calculate the total radiation on the inclined plane, and the optimum inclination angle is selected.

$$
\begin{aligned}
H_{t} & =H_{b t}(S)+H_{d t}(S)+H_{r t}(S) \\
H_{b t} & =H_{b} \times R_{b} \\
H_{d t} & =H_{d}\left[\frac{H_{b}}{H_{0}} R_{b}+0.5 \times\left(1-\frac{H_{b}}{H_{0}}\right)(1+\cos S)\right] \\
H_{r t} & =0.5 \rho H(1-\cos S)
\end{aligned}
$$

In the above formula: $\boldsymbol{H}$ - total radiation on the horizontal surface; $\boldsymbol{H}_{\boldsymbol{0}}$ - the amount of solar radiation on the surface of the outer layer of the atmosphere; $\boldsymbol{H}_{\boldsymbol{b}}$ - the amount of direct solar radiation on the horizontal plane; $\boldsymbol{H}_{b t}-$ The amount of direct solar radiation on the inclined plane; $\boldsymbol{H}_{\boldsymbol{d}}$ - the amount of scattering radiation on the horizontal plane; $\boldsymbol{H}_{\boldsymbol{d} t}$ - the amount of solar radiation on the inclined plane; $\mathrm{H}_{\mathrm{rt}}-\mathrm{The}$ reflection radiation on the surface of the tilting surface; $\mathrm{H}_{\mathrm{t}}-$ The reflection radiation on the surface of the tilting surface; $\mathrm{h}_{\mathrm{s}}$ - the sunset angle on the horizontal plane; $\mathrm{R}_{\mathrm{b}}$ - The ratio of the direct radiation on the tilting surface to the horizontal plane; $S$-The angle of the inclined plane; $\Phi$ - the latitudes of the locals; $\delta$ - The angle of the sun's declination; $\rho$ - ground reflectivity.

The PVSYST software is used to calculate the total annual radiation changes on the surface of the array under the conditions of different azimuth and dip angles, such as Figure 7 and 8.

It can be seen from the diagram that the annual total radiation on the square surface is maximum when the azimuth angle is 0 degrees and the dip angle is 19 degrees.

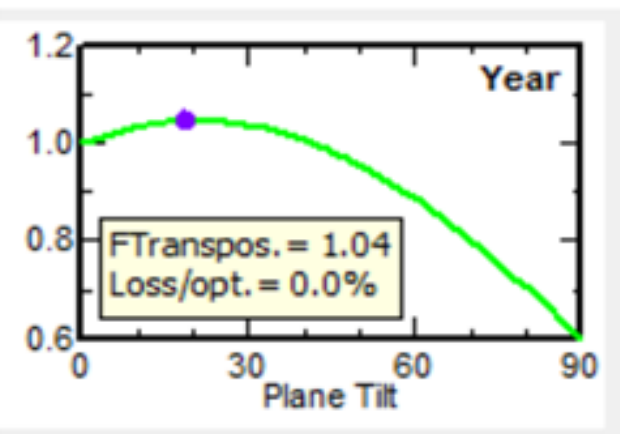

Figure 7. Irradiance diagram under different inclinations 


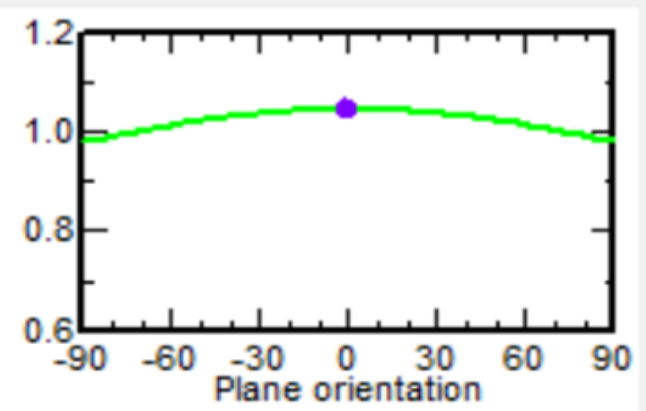

Figure 8. Angle selection of different azimuth irradiance RETScreen software is used to verify

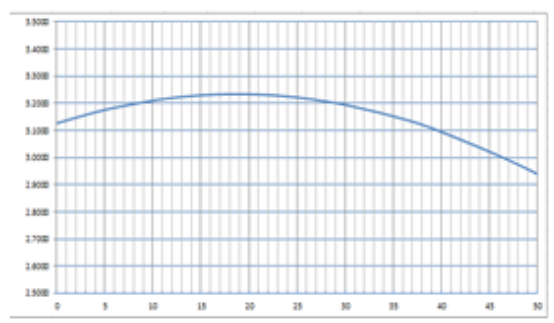

Figure 9. Variation curve of total solar radiation on different inclined surfaces

Table 3. Relative maximum value of oblique radiation at various angles.

\begin{tabular}{|c|c|c|c|}
\hline $\begin{array}{c}\text { Compone } \\
\text { nt inclination } \\
(\circ)\end{array}$ & $\begin{array}{c}\text { Amplitud } \\
\text { e ratio }(\%)\end{array}$ & $\begin{array}{c}\text { Compone } \\
\text { nt inclinatio } \\
\left({ }^{\circ}\right)\end{array}$ & $\begin{array}{c}\text { Amplit } \\
\text { ude ratio } \\
(\%)\end{array}$ \\
\hline 0 & 96.679 & 22 & 99.898 \\
\hline 5 & 98.202 & 23 & 99.825 \\
\hline 10 & 99.271 & 24 & 99.734 \\
\hline 11 & 99.429 & 25 & 99.623 \\
\hline 12 & 99.567 & 26 & 99.493 \\
\hline 13 & 99.686 & 27 & 99.345 \\
\hline 14 & 99.786 & 28 & 99.177 \\
\hline 15 & 99.867 & 29 & 98.99 \\
\hline 16 & 99.929 & 30 & 98.784 \\
\hline 17 & 99.972 & 35 & 97.475 \\
\hline 18 & 99.996 & 40 & 95.706 \\
\hline 19 & 100 & 45 & 93.513 \\
\hline 20 & 99.985 & 50 & 90.902 \\
\hline 21 & 99.951 & 60 & 84.489 \\
\hline \multicolumn{2}{|c}{} & &
\end{tabular}

It is visible from the above table that the curve has a "flat peak" in the vicinity of the inclination angle of the maximum oblique radiation.In a wider range of angles, the radiation of the inclined plane has little change.For example, the inclination angle of the slope surface radiation ratio is greater than $99.8 \%$ in the range of 16 -21 , the inclination angle of the slope radiation ratio is greater than $99.8 \%$ in the range of $15-23$, the inclination angle of the slope surface radiation ratio is more than $99.7 \%$, and the inclination angle is in the range of 14
-24.The rational use of the above analysis results can not only ensure that the power generation is not greatly affected, but also can have greater flexibility in the design of the component inclination.With the development of engineering analysis and technology, the most economical angle is also analyzed in addition to the maximum angle of power generation. To reduce the angle, the area can be greatly saved when the power generation is not damaged.Especially in areas with long high latitudes, the effect of land saving is better.To a certain extent, the influence of wind load on the PV support can be reduced to a certain extent. Under the premise of meeting the design specifications, the amount of steel used in the bracket will be reduced and the investment cost of the project will be reduced.Considering the requirements of power generation, engineering safety and investment cost, the optimal fixed dip angle of the PV array is 15 degrees.

\section{Summary}

After the construction of the photo-voltaic electric field, the proportion of renewable energy in the energy structure can be improved.The rational exploitation and utilization of solar energy is in line with the encouraging direction of national energy development, and it is the necessary need to improve the ecology and protect the environment.Photo-voltaic power generation does not generate pollutants and safety problems caused by traditional power generation technology, no exhaust or noise pollution, no sulfur dioxide, nitrogen oxides and carbon dioxide emissions.After the system is discarded, there are few remaining problems of environmental pollution.Solar energy is a clean and renewable energy, and the development of solar energy is in line with the national policy of environmental protection and energy conservation. The development and construction of large scale photo-voltaic power plants can contribute to the environmental energy crisis, which can effectively reduce the consumption of conventional energy, especially coal resources, and protect the ecological environment.After the photo-voltaic power station is built and run, a part of the green power can be provided to reduce the operation cost of the sewage plant and improve the proportion of renewable energy in the energy structure.

\section{References}

1. Wu Haoliang Photo-voltaic power generation and its application in building "Engineering technology and architectural design", 2015 (22)

2. Zang Yang Yang Research on solar energy legislation Nanjing University of Technology, 2011

3. Gu Xiaoping, Wang Ji Kang, China solar energy resources evaluation research of "Guizhou meteorology", 2011, 35 (5): 1-4

4. Chen Xingfeng, Cao Zhifeng, Xu Honghua, the maximum power of coke in strong photo-voltaic power generation tracking algorithm based on "renewable energy", 2005 (1): 8-11 
5. Xu Zhenxing, Zhou Ping, Hu to photo-voltaic power station technical and economic comparison of solar cell module Youth Conference China Institute of electrical engineering, 2012

6. Xiao Zheng Improving MPPT functional grid connected photo-voltaic inverter system research and design, North China Electric Power University (Beijing) North China Electric Power University, 2012

7. Xue Wentian Xue Wentian Research on the development strategy of University of International Business and Economics, 2013 